\title{
Comparing VA and Community-Based Care: Trends in Sleep Studies Following the Veterans Choice Act
}

\author{
Frances M. Weaver, $P h D^{1,2}$, Alex Hickok, $M A^{3}$, Bharati Prasad, $M D^{4,5}$, \\ Elizabeth Tarlov, $\mathrm{PhD}^{1,6}$, Qiuying Zhang, $\mathrm{MA}^{7}$, Amanda Taylor, $\mathrm{PhD}^{7}$, Brian Bartle, $\mathrm{MPH}^{7}$, \\ Howard Gordon, $M D^{1,4,8}$, Rebecca Young, $M A^{3}$, Kathleen Sarmiento, $M D^{9,10}$, and \\ Denise M. Hynes, $P h D^{3,11,12}$
}

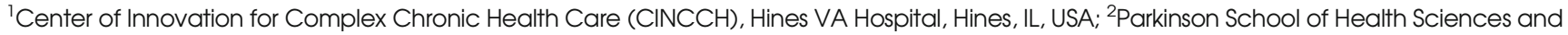
Public Health, Loyola University, Maywood, IL, USA; ${ }^{3}$ Center to Improve Veteran Involvement in Care, Portland VA Healthcare System, Portland, OR, USA; ${ }^{4}$ Jesse Brown Veterans Affairs Medical Center, Chicago, IL, USA; ${ }^{5}$ Department of Medicine, University of Illinois at Chicago, Chicago, IL, USA; ${ }^{6}$ College of Nursing, University of Illinois at Chicago, Chicago, IL, USA; ${ }^{7}$ VA Information Resource Center, Department of Veterans Affairs, Hines VA Hospital, Hines, IL, USA; ${ }^{8}$ Section of Academic Internal Medicine, Department of Medicine, University of Illinois at Chicago, Chicago, IL, USA; ${ }^{9}$ Department of Medicine, University of California, San Francisco, San Francisco, CA, USA; ${ }^{10}$ Center for Healthcare Improvement \& Medical Effectiveness, San Francisco VA Healthcare System, San Francisco, CA, USA; ${ }^{11}$ College of Public Health and Human Sciences \& Center for Genome Research and Biocomputing, Oregon State University, Corvallis, OR, USA; ${ }^{2}$ School of Nursing, Oregon Health and Science University, Portland, OR, USA.
\end{abstract}

BACKGROUND: To address concerns about access to care, the Veterans Access, Choice, and Accountability Act of 2014 was enacted to make care available in the community when Veterans Health Administration (VA) care was unavailable or not timely. This paper examined VA referrals for diagnostic sleep studies from federal fiscal year (FY) 2015-2018.

DESIGN: Sleep studies completed between FY2015 and 2018 for Veterans tested within VA facilities (VAF) or referred to VA community care (VACC) providers were identified using VA administrative data files. Sleep studies were divided into laboratory and home studies.

KEY RESULTS: The number of sleep studies conducted increased over time; the proportion of home studies increased in VAF (32 to $47 \%$ ). Veterans were more likely to be referred for a sleep study to VACC if they lived in a rural or highly rural area (ORs $=1.47$ and 1.55 , respectively), and had public or public and private insurance $(\mathrm{ORs}=2.01$ and 1.35), and were less likely to be referred to VACC if they were age $65+(\mathrm{OR}=0.72)$ and were in the highest utilization risk based on Nosos score (OR $=0.78)$. Regression analysis of sleep study type revealed that lab studies were much more likely for VACC referrals $(\mathrm{OR}=3.16)$, for persons living in rural areas $(\mathrm{OR}=1.21)$, with higher comorbidity scores $(\mathrm{OR}=1.28)$ and for ages $44-54,55$ to 64 , and $65+(\mathrm{ORs}=$ $1.12,1.28,1.45$, respectively) compared to younger Veterans. Veterans with some or full VA copayments (ORs $=0.91$ and 0.86, respectively), and overweight Veterans $(\mathrm{OR}=0.94)$ were less likely to have lab studies.

CONCLUSIONS: The number of sleep studies performed on Veterans increased from 2015 to 2018 . Access to sleep studies improved through a combination of providing care through the Veteran Choice Program, predominantly

This work was presented at the VA HSR\&D/BUERI 2019 National Conference, Washington, D.C., Oct. 29-31, 2019.

Received November 5, 2019

Accepted March 12, 2020

Published online April 2, 2020 used by rural Veterans, and increased use of home sleep studies by VA.

KEY WORDS: Veterans; access; sleep studies; community care; VA Choice Act.

Abbreviations
VACC
OR
VCP
VAF
VA
BMI
OSA
FY
CDW
CPT

VA community care odds ratio Veterans Choice Program VA facilities Veterans Health Administration body mass index obstructive sleep apnea fiscal year corporate data warehouse common procedure terminology

$\mathrm{J}$ Gen Intern Med 35(9):2593-9 DOI: $10.1007 / \mathrm{s} 11606-020-05802-5$ (C) Society of General Internal Medicine (This is a U.S. government work and not under copyright protection in the U.S.; foreign copyright protection may apply) 2020

\section{BACKGROUND}

As a result of national concerns about Veterans' access to VA care, Congress passed the Veterans Access, Choice, and Accountability Act of 2014 (Public Law 113-146) ("Veterans Choice Act") and, as amended (Public Law 113-175), aimed to improve access to timely, high-quality health care. The Veterans Choice Program (VCP) allowed VA to expand its long-standing fee-basis and contract care programs (VA-paid care provided by non-VA providers) to include a new option for VA-paid community-based care. Veterans' eligibility for care through the VCP was based on VA appointment wait time greater than 30 days, distance (living 40 miles or greater from the nearest VA medical facility), or hardship (significant 
burdens to travel to VA for care). By federal fiscal year (FY) 2017, about 1.5 million Veterans had received care in the community through the VCP. ${ }^{1}$ VA community care has since been consolidated into a single program and expanded as part of the VA MISSION Act of 2018 (Public Law 115-182).

One of the areas that the VCP addressed was Veterans' access to specialty care services. Sleep medicine is an example of specialty care that is important for Veterans' health care due to the high prevalence of sleep disorders among Veterans and their significant sequelae. Conditions such as obstructive sleep apnea (OSA) remain undiagnosed in most of the affected population. ${ }^{2,}{ }^{3}$ Estimates suggest OSA is common in the general population, affecting 5-10\% of adults. ${ }^{4}$ Among Veterans receiving care in the VA, prevalence estimates based on diagnosed OSA are similar (4.5\% among patients receiving care between 2000 and 2010), ${ }^{5}$ though considerably higher in some subgroups including those with cardiovascular disease, cancer, and post-traumatic stress disorder. Several studies based on symptom reports suggest that true prevalence of OSA in Veterans may be much higher $(42-66 \%))^{2,6,7}$ OSA is associated with coronary artery disease, incident stroke, and higher mortality. ${ }^{8}$ In a national study, Alexander et al. ${ }^{5}$ found sleep apnea $(47 \%)$ and insomnia $(26 \%)$ to be the most common disorders among Veterans with any sleep problems. Further, over the course of their 11-year study, they found a sixfold increase in sleep disorder diagnoses in Veterans seen in VA facilities.

Definitive diagnosis of OSA and other sleep disorders usually requires a diagnostic sleep study. Laboratory sleep studies, or polysomnography, require an overnight stay in a sleep laboratory where electroencephalography, respiratory effort, oxygen saturation, heart rhythm, and muscular response are monitored. Home sleep studies are also an option with the patient being sent home with a portable monitor. The biggest difference in these studies is that the home study does not use electroencephalography and only addresses the question of whether sleep apnea is present or absent. Home sleep testing devices are convenient in that they can be mailed to the patient or given to the patient at a local VA outpatient clinic to take home. The patient wears the device during sleep and the device records information used to determine whether there is evidence of sleep-disordered breathing. Upon return of the device to VA, the data are uploaded for review and interpretation by a sleep provider. The clinical practice guideline for diagnostic testing of sleep apnea recommends that either polysomnography or home sleep testing is appropriate for diagnosis of sleep apnea in uncomplicated adult patients. ${ }^{9}$ Given the high demand for sleep studies in the VA and limited access to in-laboratory sleep testing, increasing numbers of Veterans are being referred for studies at home or through a community provider.

The purpose of this paper was to examine access to sleep studies by location of care (VA facilities (VAF) or VA community care (VACC)) for Veterans with suspected OSA during the first 4 years of the VCP, FY2015-2018.

\section{METHODS}

We utilized a retrospective cohort design to compare Veterans who received consults for sleep studies completed in a VAF with Veterans who received referrals to VACC. Data were collected from VA's corporate data warehouse (CDW), a comprehensive set of data files on patient characteristics, health conditions, and health care utilization that is both national and longitudinal in scope ${ }^{10}$ Information on patient demographics and clinical characteristics, VA outpatient care and scheduling, and VA Community Care program authorization and claims were extracted for analysis.

\section{Study Cohort}

To identify Veterans who were referred for and received a sleep study between FY2015 and 2018, we used common procedure terminology (CPT) version 4 codes used for sleep studies in the lab and home. In consultation with sleep medicine providers, we selected CPT codes for in-lab $(95805,05807,95808,95810)$ and home sleep studies (95800, 95801, 98806, G0298, G0399, G0400) in VA and VACC outpatient records.

For the sleep studies identified, we included only those for which there was a date recorded for the initial sleep study, and in the case of VACC, that there was a paid claim for the procedure. VAF sleep study visits were matched with a date when the appointment was scheduled in VA. VACC sleep studies were matched with the date of the nearest Community Care authorization for the sleep study-specific category of care for VACC in case a Veteran had more than one procedure ordered. We excluded visits that were not matched with either method, and visits for patients that received sleep testing in both care settings during the study period (see Fig. 1).

Our covariates included demographics (age, marital status, race), VA copayment status, health insurance coverage, rural status, comorbidity, and body mass index (BMI). Age was defined as a categorical variable $(<45$, $45-54,55-64,65$ and older); marital status was consolidated as a dummy variable (single versus married); and race was a three-level variable (white, black, or other). For VA copayment, we defined three groups (no, some, or full copay). Insurance status was categorized based on having only VA coverage, only private insurance, only public insurance, or a combination of coverage and insurance (none, private, public, private + public). Rural status was based on the Veterans' recorded residence in one of three categories (urban, rural, highly rural). We also calculated the distance to the nearest VA facility or clinic (in miles). For comorbidity risk adjustment, we considered several measures. We included the Nosos score, designed to predict VA costs. Nosos scores are centered around the value of 1 indicating expected costs at the national average for VA patients; higher than one indicates greater risk while $<1$ indicates lower cost 


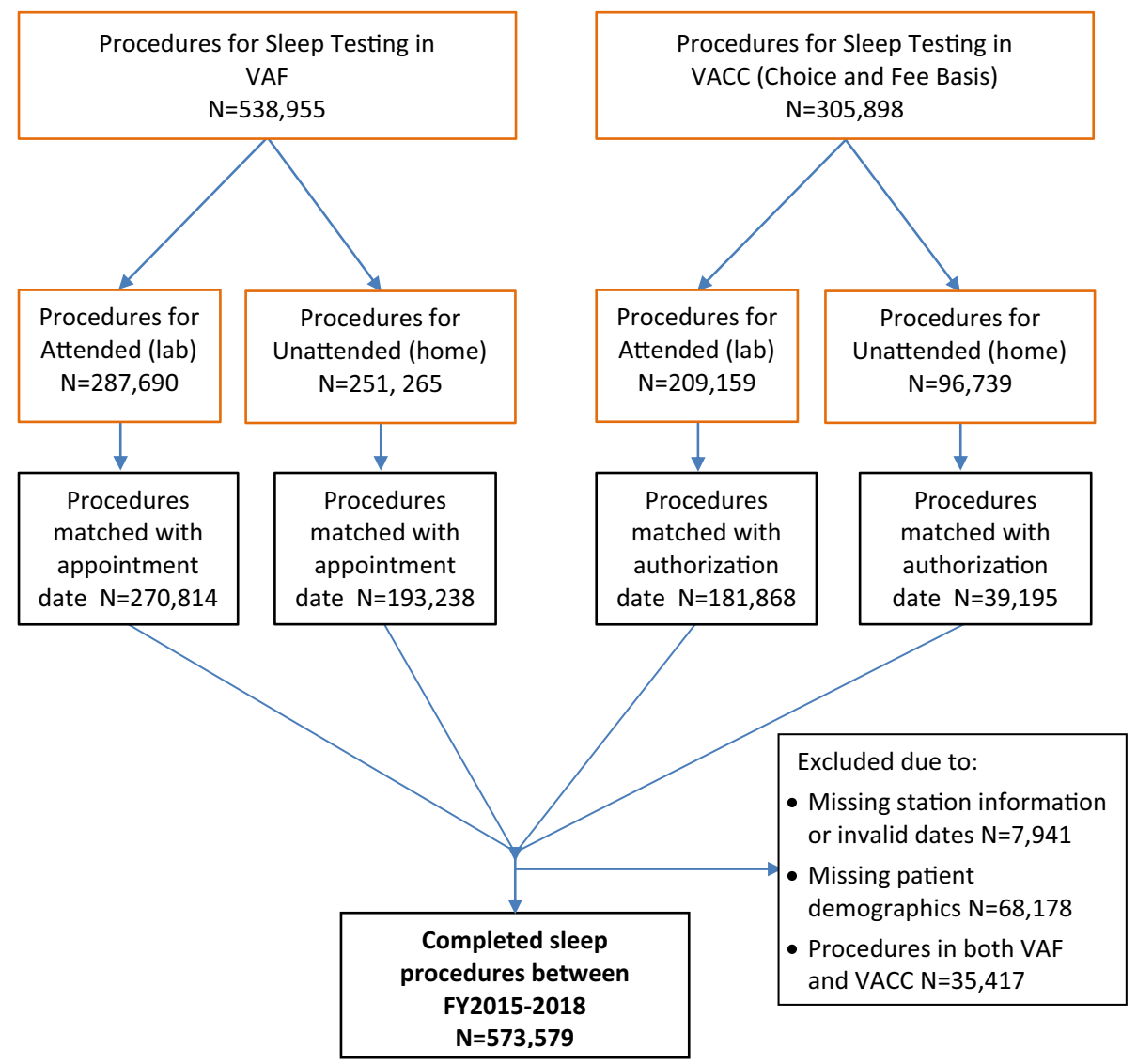

Figure 1 Sleep test procedure cohort derivation.

risk. ${ }^{11}$ We calculated the concurrent year Nosos scores. In addition, we calculated an adapted version of the Charlson comorbidity index. ${ }^{12}$ We included BMI as it is highly associated with $\mathrm{OSA}^{13},{ }^{14}$; we grouped BMI as a three-level variable (normal, overweight, obese).

\section{Analysis}

Comparisons of Veterans who were referred for sleep studies to VACC with Veterans who had sleep studies done in a VAF were conducted using bivariate analyses. We also compared those who completed home sleep studies to those who had lab-based sleep studies. Due to the large samples, we utilized standardized mean differences (SMD) to compare groups on a univariate basis. SMD is a type of effect size, also known as Cohen's $d$, with larger values indicating a greater effect or differences between groups. ${ }^{15}$

We used logistic regression analyses to determine those characteristics that were associated with receipt of care in VACC versus VAF. We also examined factors associated with whether the procedure was performed at home or in a sleep lab. Standard errors for regression coefficients were adjusted using robust clustering by VA facility. ${ }^{16}$ Analyses were performed with $\mathrm{R}$ version $3.5 .3^{17}$ and clustering was estimated using the multiwayvcov package. ${ }^{18}$

\section{RESULTS}

Between FY2015 and 2018, there were over 573,000 sleep studies completed at either VAF or VACC settings. Analyses were based on sleep study referrals for which we had complete data for the date of testing and patient characteristics ( $n=$ 573,579) (see Fig. 1). A comparison of patient characteristics by location is provided in Table 1. Overall, the characteristics of patients who had their sleep study done in VAF or in VACC sites were similar. The mean age of Veterans who received sleep studies was 55 years, 90\% were male, and the average BMI was 33 (obese category). The largest differences between the VAF and VACC patients were insurance status and rural status. Eighteen percent of Veterans who received sleep studies in VAF had no other health insurance beyond VA coverage, compared with $14 \%$ of those who had sleep studies in VACC $(\mathrm{SMD}=0.237)$. Further, those Veterans who had their sleep studies in VACC more often had only public insurance $(41 \%)$ than those who had testing in VAF (30\%). Veterans who lived in rural or highly rural areas more often had their sleep studies done in VACC $(39.7 \%)$ than those living in urban areas $(28.7 \%)(\mathrm{SMD}=0.234)$. Higher percentages of Veterans with diabetes, chronic heart failure, or chronic obstructive lung disease received in-lab testing in either VA or the community than Veterans without these conditions (results not shown). 
Table 1 Patient Characteristics by Referral Location (VAF or VACC $)(N=467,377)$

\begin{tabular}{|c|c|c|c|}
\hline Variable & $\begin{array}{l}\text { VAF }(N= \\
330,888)\end{array}$ & $\begin{array}{l}\text { VACC }(N= \\
136,489)\end{array}$ & SMD* \\
\hline Age, years (mean/SD) & $54.89(15.0)$ & $55.0(14.76)$ & 0.0132 \\
\hline Age categories & & & 0.014 \\
\hline$<45$ years & $26.9 \%$ & $26.3 \%$ & \\
\hline $45-54$ years & $19.0 \%$ & $19.1 \%$ & \\
\hline 55-64 years & $21.5 \%$ & $21.4 \%$ & \\
\hline $65+$ years & $32.6 \%$ & $33.2 \%$ & \\
\hline Male $(\%)$ & $90.0 \%$ & $90.3 \%$ & 0.010 \\
\hline Race $(\%)$ & & & 0.153 \\
\hline White & $70.8 \%$ & $76.7 \%$ & \\
\hline Black & $26.1 \%$ & $19.7 \%$ & \\
\hline Other & $3.1 \%$ & $3.6 \%$ & \\
\hline Hispanic (\%) & $8.1 \%$ & $8.8 \%$ & 0.026 \\
\hline Marital status (\%) & & & 0.085 \\
\hline Single & $45.1 \%$ & $40.9 \%$ & \\
\hline Comorbidity $>1^{\dagger}$ & $17.4 \%$ & $16.9 \%$ & 0.014 \\
\hline Nosos category & & & 0.062 \\
\hline Q1 & $25.0 \%$ & $25.0 \%$ & \\
\hline Q2 & $24.6 \%$ & $25.9 \%$ & \\
\hline Q3 & $24.7 \%$ & $25.8 \%$ & \\
\hline Q4 & $25.7 \%$ & $23.2 \%$ & \\
\hline $\mathrm{BMI}^{\S}$ & 20.18 & 25.210 & 0.019 \\
\hline Normal & $8.1 \%$ & $7.7 \%$ & \\
\hline Overweight & $27.8 \%$ & $27.3 \%$ & \\
\hline Obese & $64.1 \%$ & $65.0 \%$ & \\
\hline Veteran copay & & & 0.057 \\
\hline None & $55.0 \%$ & $57.6 \%$ & \\
\hline Some & $34.5 \%$ & $33.0 \%$ & \\
\hline Full copay & $10.5 \%$ & $9.4 \%$ & \\
\hline Insurance & & & 0.237 \\
\hline None & $18.1 \%$ & $13.9 \%$ & \\
\hline Private & $46.6 \%$ & $40.4 \%$ & \\
\hline Public & $29.8 \%$ & $40.9 \%$ & \\
\hline Both & $5.5 \%$ & $4.8 \%$ & \\
\hline Rural status (\%) & & & 0.234 \\
\hline Urban & $71.3 \%$ & $60.3 \%$ & \\
\hline Rural & $27.8 \%$ & $38.2 \%$ & \\
\hline Highly rural & $0.9 \%$ & $1.5 \%$ & \\
\hline $\begin{array}{l}\text { Miles to nearest VA } \\
(\text { mean/SD) }\end{array}$ & 14.7 (13.2) & $17.0(17.4)$ & 0.150 \\
\hline
\end{tabular}

*SMD = effect size; small, medium, large (due to very large sample sizes, SMD is a more accurate representation of differences than traditional $p$ values)

FComorbidity is based on the Charlson score calculated on the year prior to the patient's sleep consult/referral. Scores were dichotomized into low (score of 1.0 or less) and high (score of $>1.0$ )

tNosos is a risk adjustment score as to whether a patient is more or less likely to have similar health care costs as the average patient. The average patient scores a 1; less than 1 indicates lower expected costs and greater than 1 indicates higher expected costs

$\S B M I$ body mass index

The total number of sleep studies increased annually, while the percent completed in VAF versus VACC remained relatively stable (69\% versus $31 \%$ ). The proportion of home sleep studies in VACC remained around 18\% for each year examined, while the proportion of home tests in VAF increased from $33 \%$ in FY2015 to $48 \%$ by FY2018 (see Fig. 2).

Regression analysis of location of testing (VAF versus VACC) revealed that Veterans living in rural or highly rural areas were more likely to have their sleep studies in VACC than VAF (ORs $=1.47$ and 1.55 , respectively) (see Table 2). Distance to nearest VA facility or clinic was not associated with location of care. Regarding insurance status, Veterans who had any public insurance/Medicaid were more likely to have received their sleep studies in VACC. Sleep studies performed in VACC were less likely for Veterans who have some $(\mathrm{OR}=0.90, \mathrm{CI}=0.84-0.97 ; p<.01)$ or full VA copayments $(\mathrm{OR}=0.83, \mathrm{CI}=0.76-0.91 ; p<.001)$, and for those who were single, were 65 years or older, and had the highest Nosos risk scores (see Table 2).

Characteristics that distinguished lab from home sleep studies also were identified using regression analysis (see Table 3). Lab studies were much more likely to be provided through VACC than VAF (OR $=3.16, \mathrm{CI}=2.23-4.48)$. Also, Veterans with higher comorbidity ( $>1$ on Charlson scale), those in age categories over age 44, and Veterans living in rural areas were more likely to have a lab sleep test. Veterans who were overweight had a decreased probability of having a lab sleep study $(\mathrm{OR}=0.94,95 \% \mathrm{CI}=0.89-0.99 ; p<.05)$ compared with those who were normal weight, as were Veterans with some or full VA copays $(p s<0.001)$.

\section{DISCUSSION}

We observed several trends in diagnostic sleep study utilization among Veterans after enactment of the VCP. First, we observed that the number of patients who had sleep studies increased over time. This growth in the volume of sleep studies is likely due to a combination of improved access to testing through the $\mathrm{VCP}$ and the increased recognition of sleep problems in the Veteran population. ${ }^{5}$ Further, the trend in sleep studies performed for Medicare beneficiaries also has increased by $9.1 \%$ since $2010 .{ }^{19}$ Figure 2 shows the increase in the number of sleep studies from approximately $120 \mathrm{~K}$ veterans in FY2015 to over $161 \mathrm{~K}$ veterans in FY2018, a $34 \%$ increase. Interestingly, the increase was more pronounced for testing done within VAF. Our results are consistent with the overall trend of increased use of sleep testing and in recognition that sleep apnea is underdiagnosed and undertreated. ${ }^{20}$

The second trend observed was the increase in the use of home studies in VAF. This trend was not present for VACC sleep studies. Use of home sleep studies instead of lab studies has increased in many VA hospitals to address issues of timeliness and cost. ${ }^{21,22}$ Furthermore, the national VA Sleep Medicine program office has actively encouraged more home sleep studies, a VA best practice since 2014. Medicare has also seen a dramatic growth in home sleep studies from less than $1 \%$ in 2000 to $12 \%$ in $2014,{ }^{19}$ reflecting increased adoption following approval of home sleep testing for reimbursement in 2008.

During this same timeframe, VA promoted widespread adoption of telehealth services to improve Veterans' access to care. The TeleSleep program, funded by the VA Office of Rural Health, specifically promoted the expansion of home sleep testing, an asynchronous form of store-and-forward telehealth (i.e., data, image/photo, or video is acquired from a patient, stored, and forwarded to/retrieved by a provider at a 


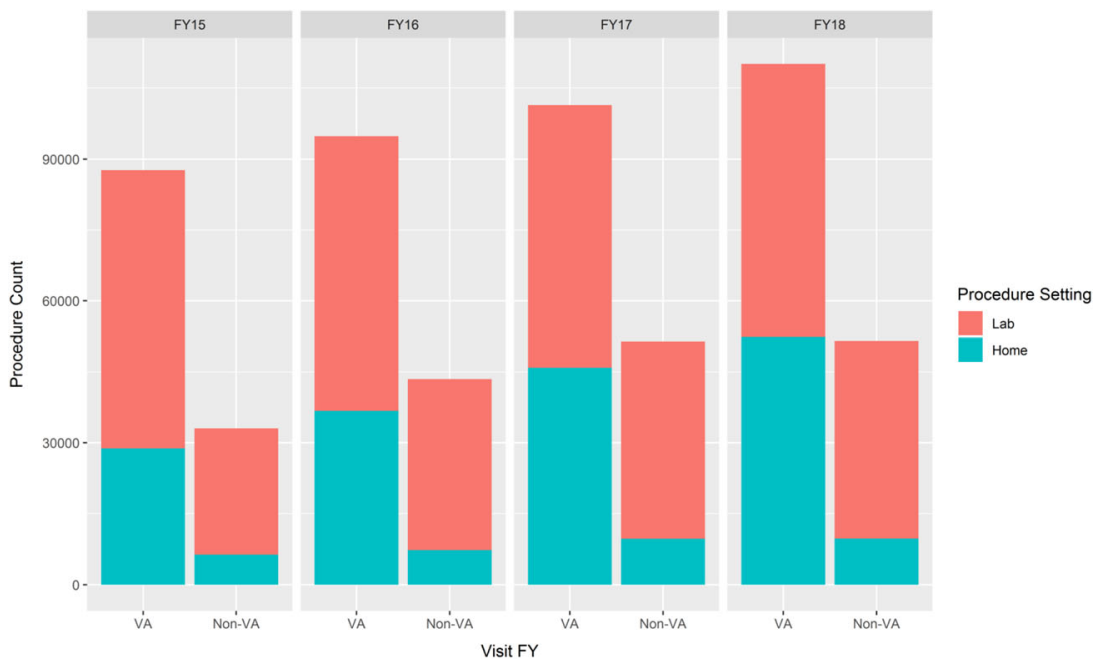

Figure 2 Sleep tests by VA and community FY2015-2018.

different time for clinical evaluation), and provided 54 VA facilities with home sleep testing recorders to facilitate accomplishing this goal. ${ }^{23}$ In FY2018, more than 782,000 patients received some care through telehealth, including over 52,000 sleep-testing visits. ${ }^{23}$ Telehealth enables access to care through use of information and telecommunication technologies, which is especially useful and feasible for Veterans who live in rural areas. ${ }^{24,25}$ Home sleep testing allows VA to provide care within VA by making it available to Veterans who live in rural areas, where non-VA services may be equally hard to come by. These devices can be mailed to the Veteran, reducing the need to come into the facility for testing. Home sleep testing represents the most rapidly growing telehealth storeand-forward program in VA.

Table 2 Independent Predictors of the Use of VACC Compared with VAF for Sleep Studies $(N=467,377)$

\begin{tabular}{|c|c|c|c|}
\hline & OR estimate & $95 \% \mathrm{CI}$ & $p$ value \\
\hline Intercept & 0.37 & $0.16-0.89$ & 0.05 \\
\hline BMI* - overweight & 1.02 & $0.98-1.06$ & Ns \\
\hline BMI*_obese & 1.05 & $0.99-1.11$ & Ns \\
\hline Some copay & 0.90 & $0.84-0.97$ & 0.01 \\
\hline Full copay & 0.83 & $0.76-0.91$ & 0.001 \\
\hline Age $45-54$ years & 1.02 & $0.96-1.09$ & Ns \\
\hline Age $55-64$ years & 0.95 & $0.84-1.08$ & Ns \\
\hline Age $65+$ years & 0.72 & $0.55-0.96$ & .05 \\
\hline Male & 0.97 & $0.89-1.05$ & Ns \\
\hline Black & 0.80 & $0.63-1.02$ & 0.10 \\
\hline Other race & 1.10 & $0.83-1.45$ & Ns \\
\hline Marital status - single & 0.88 & $0.83-0.92$ & 0.001 \\
\hline Rural & 1.47 & $1.20-1.80$ & 0.001 \\
\hline Highly rural & 1.55 & $1.11-2.15$ & 0.01 \\
\hline Nosos Q2 $2^{\dagger}$ & 0.99 & $0.95-1.04$ & Ns \\
\hline Nosos Q3 ${ }^{\dagger}$ & 0.95 & $0.88-1.02$ & Ns \\
\hline Nosos Q $4^{\dagger}$ & 0.78 & $0.68-0.88$ & 0.001 \\
\hline Miles to nearest VA & 1.00 & $1.00-1.01$ & Ns \\
\hline Private insurance & 1.09 & $0.97-1.23$ & Ns \\
\hline Public insurance & 2.01 & $1.11-3.65$ & 0.05 \\
\hline Public and private insurance & 1.35 & $1.15-1.59$ & 0.001 \\
\hline
\end{tabular}

*BMI body mass index

+Nosos is a risk adjustment score as to whether a patient is more or less likely to have similar health care costs as the average patient. The average patient scores a 1; less than 1 indicates lower expected costs and greater than 1 indicates higher expected costs
Community providers may have a lower rate of adoption of home sleep testing due to lower reimbursement compared to laboratory studies, and thus may not be equipped to offer this option for Veterans seeking sleep testing through VACC. Recent data indicate that the cost of home sleep testing is $74 \%$ less than that of laboratory testing. ${ }^{26}$ The low use of home sleep studies in the community alternatively may be due to the possibility that community providers are not willing to use home sleep studies for persons with comorbid conditions such as heart failure, morbid obesity, and moderate to severe chronic obstructive pulmonary disease, as home sleep apnea testing has not been validated in patients with preexisting conditions, potentially leading to inconclusive findings. Our finding that older Veterans were significantly more likely to receive in-lab studies is consistent with this hypothesis and is worthy of further study.

Persons living in rural areas more often had sleep studies conducted in the community. This trend directly addresses

Table 3 Independent Predictors of Lab Compared with Home Sleep Studies $(N=467,377)$

\begin{tabular}{|c|c|c|c|}
\hline & OR estimate & $95 \% \mathrm{CI}$ & $p$ value \\
\hline Intercept & 1.54 & $1.08-2.21$ & 0.05 \\
\hline BMI* overweight & 0.95 & $0.90-0.99$ & 0.05 \\
\hline BMI*_obese & 0.99 & $0.90-1.08$ & $\mathrm{Ns}$ \\
\hline Age $45-54$ years & 1.15 & $1.07-1.18$ & 0.001 \\
\hline Age $55-64$ years & 1.27 & $1.19-1.36$ & 0.001 \\
\hline Age $65+$ years & 1.41 & $1.28-1.56$ & 0.001 \\
\hline Male & 1.03 & $0.97-1.09$ & Ns \\
\hline Single (versus married) & 0.97 & $0.93-1.02$ & $\mathrm{Ns}$ \\
\hline Black & 1.00 & $0.84-1.20$ & $\mathrm{Ns}$ \\
\hline Other race & 0.92 & $0.64-1.31$ & Ns \\
\hline Comorbidity $^{\dagger}$ & 1.25 & $1.16-1.35$ & 0.001 \\
\hline Rural & 1.31 & $1.09-1.58$ & 0.01 \\
\hline Highly rural & 1.33 & $0.96-1.85$ & 0.10 \\
\hline Some copay & 0.90 & $0.85-0.95$ & 0.001 \\
\hline Full copay & 0.83 & $0.77-0.90$ & 0.001 \\
\hline Miles to nearest VA & 1.00 & $1.00-1.00$ & Ns \\
\hline
\end{tabular}

*BMI body mass index

†Comorbidity was a dichotomized variable using the Charlson index. Persons with a comorbid score of 1 or less versus persons with a comorbidity score $>1.0$ 
VCP's goal of increasing access to care by increased Veteran engagement in local communities in addition to reducing travel burden. Sleep studies were more commonly done in VA for elderly Veterans and those with the highest Nosos utilization risk scores, suggesting that VA may continue to manage those at greater risk within VA. As follow-up care would most likely occur within VA for these individuals, coordination of care across providers will be increasingly important to ensure satisfactory patient outcomes. ${ }^{27,} 28$

Data from the first years of VCP indicate that many VA providers did not like the program for care in general because they experienced problems with care coordination and continuity between VA and community specialists. ${ }^{29}$ Coordination of care across non-integrated health care systems in the VCP places the onus on the patient/caregiver to manage scheduling, track down test results, and submit prescriptions for medications and prosthetic devices back to VA. ${ }^{30}$ Concerns also have been raised about duplication of effort, such as repeat testing when access to community records is problematic. ${ }^{11}$ As the VCP has evolved, VA facilities and providers may have sought alternative strategies to encourage Veterans to seek care at VA facilities for evaluation and treatment. In response to VA's priority of providing timely care to Veterans when they want it and where they want it, VA programs may need further innovation regarding health information technology and implementation strategies to ensure access to and coordination of care. $^{31}$

VA sleep programs are opting to use home sleep studies and are incorporating other telehealth strategies so Veterans have less need to seek care from community providers. ${ }^{21,25,32}$ This approach of consolidating care at a VA facility may be particularly important in reducing the burden of coordinating VA procurement of equipment needs for Veterans related to treating any sleep problems identified. Patients with OSA are usually provided with a CPAP device to manage their condition. There are reports of delays in receiving testing reports and treatment recommendations from community testing sites results in delays in procuring the needed equipment, delaying the start of treatment (personal communication, K. Sarmiento, MD, National Lead VHA TeleSleep; August 7, 2019). Communication and coordination of care between VA and community providers are areas requiring further examination.

There were several limitations to this study. We excluded cases with missing data, which may have biased our sample. We were reliant on administrative data for a new program. It is likely that there were errors, missing data, and other limitations with these data. However, our data are consistent with information reported by the national VA sleep program regarding increased volume of sleep testing and use of home testing, ${ }^{22}$ which enhances its generalizability. Specifically, the overall demand for sleep evaluations continues to rise 6$10 \%$ annually, diagnostic testing is increasing at similar rates (with marked growth in home testing volumes), and the use of sleep telehealth in rural facilities served by the TeleSleep program is associated with a reduction in community care utilization. $^{32}$

\section{CONCLUSION}

Access to sleep studies increased in the first 4 years following the implementation of the VA Choice Act. Use of VA-authorized community providers for sleep studies was more common for Veterans living in rural areas, as would be expected. In addition, we saw a large increase in use of home sleep studies by VA facilities during this timeframe. VA-authorized community providers did not similarly increase their use of this modality. Home testing minimizes the burden on Veterans with reduced travel burden to the patient. Keeping care within VA also facilitates providers' ability to coordinate care. The VCP offers a means to access health care if availability, timing, or distance to VA care is an issue. Together, VCP and home testing increased access to sleep testing for Veterans.

Corresponding Author: Frances M. Weaver, PhD; Center of Innovation for Complex Chronic Health Care (CINCCH)Hines VA Hospital, Hines, IL, USA (e-mail: Frances.Weaver@va.gov).

Funding Information This study was funded by the Health Services Research and Development Service, Department of Veterans Affairs (SDR 17-155 and SDR 18-321). Dr. Weaver is also supported by a Research Career Scientist award (RCS 98-354).

\section{Compliance with Ethical Standards:}

Ethics Approval: The analyses were approved by the Institutional Review Board at the Edward Hines, Jr. VA (IRB no. 1375113) and VA Portland Health Care System (IRB no. 04303). A waiver of informed consent was granted for this retrospective study using a large administrative database.

Conflict of Interest: The authors have no conflicts other than funding from VA's HSR\&D service for this research activity (Weaver, Tarlov, Hynes).

Disclaimer: The views expressed in this paper do not reflect the views of the Department of Veterans Affairs or the US Government.

\section{REFERENCES}

1. Mattocks KM, Yehia B. Evaluating the Veterans Choice Program: Lessons for developing a high-performing integrated network. Medical Care. 2017;55:1-3.

2. Taylor SS, Hughes JM, Coffman CJ, et al. Prevalence of and characteristics associated with insomnia and obstructive sleep apnea among veterans with knee and hip osteoarthritis. BMC Musculoskeletal Disorders. 2018;19(1):79.

3. Kapur V, Strohl KP, Redline S, Iber C, O'connor G, Nieto J. Underdiagnosis of sleep apnea syndrome in U.S. communities. Sleep and Breathing. 2002;6(2):49-54.

4. Young T, Peppard PE, Gottlieb DJ. Epidemiology of obstructive sleep apnea: a population health perspective. Am J Respir Crit Care Med. 2002;165(9):1217-39.

5. Alexander M, Ray MA, Hébert JR, et al. The National Veteran Sleep Disorder Study: Descriptive epidemiology and secular trends, 2000-2010. Sleep. 2016;39(7):1399-410. 
6. Seelig AD, Jacobson IG, Smith B, et al. Sleep patterns before, during, and after deployment to Iraq and Afghanistan. Sleep. 2010;33(12):161522.

7. Mustafa M, Erokwu N, Ebose I, Strohl K. Sleep problems and the risk for sleep disorders in an outpatient veteran population. Sleep and Breathing. 2005;9(2):57-63.

8. Molnar MZ, Mucsi I, Novak M, et al. Association of incident obstructive sleep apnoea with outcomes in a large cohort of US veterans. Thorax. 2015;70(9):888-95.

9. Kapur VK, Auckley DH, Chowdhuri S, et al. Clinical practice guideline for diagnostic testing for adult obstructive sleep apnea: an American academy of sleep medicine clinical practice guideline. J Clin Sleep Med. 2017;13(3):479-504.

10. US Department of Veterans Affairs. Veterans Health Administration (VHA) Corporate Data Warehouse (CDW). Fed Regist. 2014;79(17):437779 .

11. Rosen AK, Wagner TH, Pettey WB, et al. Differences in risk scores of Veterans receiving community care purchased by the Veterans Health Administration. Health Services Research. 2018;53:5438-54.

12. Charlson M, Szatrowski TP, Peterson J, Gold J. Validation of a combined comorbidity index. Journal of Clinical Epidemiology. 1994;47:1245-51.

13. Feher M, Hinton W, Munro N, de Lusignan S. Obstructive sleep apnoea in Type 2 diabetes mellitus: Increased risk for overweight as well as obese people included in a national primary care database analysis. Diabetic Medicine. 2019;36,1304-11.

14. Wang $\mathbf{F}$, Xiong $\mathbf{W}, \mathbf{X u} \mathbf{H}$, et al. The association between obstructive sleep apnea syndrome and metabolic syndrome: A confirmatory factor analysis. Sleep Breath. 2019;23(3):1011-19.

15. Cohen J. Statistical Power Analysis for the Behavioral Sciences. Hillsdale, NJ: L. Erlbaum Associates; 1988.

16. Cameron AC, Gelbach JB, Miller DL. Robust inference with multiway clustering. Journal of Business \& Economic Statistics. 2011;29(2):23849.

17. R Development Core Team. R: A language and environment for statistical computing. Vienna: R Foundation for Statistical Computing. Version 3.5.3. 2019. Available at: https://www.r-project.org/. Accessed 12 Apr 2019

18. Graham N, Arai M, Hagströmer B. multiwayvcov: Multi-way standard error clustering, version 3.5.3. 2019. https://cran.r-project.org/package=multiwayvcov. Accessed 12 July 2019.

19. Chiao W, Durr ML. Trends in sleep studies performed for Medicare beneficiaries. The Laryngoscope. 2017;127(12):2891-6.

20. American Academy of Sleep Medicine. Hidden health crisis costing Americans billions: Underdiagnosing and undertreating obstructive sleep apnea draining healthcare system. 2016. Available at: https://aasm.org/ advocacy/initiatives/economic-impact-obstructive-sleep-apnea/. Accessed 29 Jan 2020.

21. Biag MM, Antonescu-Turcu A, Ratarasam K. Impact of sleep telemedicine protocol in management of sleep apnea: a 5-year experience. Telemedicine and e-Health. 2016:458-462.

22. Cairns A, Sarmiento K, Bogan R. Utility of home sleep apnea testing in high-risk veterans. Sleep and Breathing. 2017;21(3):647-55.

23. Sarmiento, KF, Folmer RL, Stepnowsky CJ, et al. National expansion of sleep telemedicine for Veterans: The TeleSleep Program. Journal of Clinical Sleep Medicine. 2019;15(10):1355-64.

24. US Department of Veterans Affairs. VA telehealth services fact sheet. Available at: https://www.va.gov/COMMUNITYCARE/docs/news/VA Telehealth_Services.pdf. Accessed 5 May 2019.

25. Fields BG, Behari PP, Mccloskey S, et al. Remote ambulatory management of Veterans with obstructive sleep apnea. Sleep. 2016;39(3):501-9.

26. Donovan LM, Coggeshall SS, Spece LJ, et al. Use of in-laboratory sleep studies in the Veterans Health Administration and community care [letter] Am J Respir Crit Care Med. 2019;200(6):779-82.

27. Greenstone CL, Peppiatt J, Cunningham K, et al. Standardizing care coordination within the Department of Veterans Affairs. Journal of General Internal Medicine. 2019;34(S1):4-6.

28. Cordasco KM, Hynes DM, Mattocks KM, Bastian LA, Bosworth HB, Atkins D. Improving care coordination for Veterans within VA and across healthcare systems. Journal of General Internal Medicine. 2019;34(S1): 1-3.

29. Nevedal AL, Wagner TH, Ellerbe LS, Asch SM, Koenig CJ. A qualitative study of primary care providers' experiences with the Veterans Choice Program. Journal of General Internal Medicine. 2019;34(4):598-603.

30. Mattocks KM, Yano EM, Brown A, Casares J, Bastian L. Examining women veterans' experiences, perceptions, and challenges with the veterans choice program. Med Care. 2018;56:557-60.

31. Kilbourne AM, Hynes, DM, O'Toole T, Atkins D. A Research Agenda for Care Coordination for Chronic Conditions: Aligning Implementation, Technology, and Policy Strategies. Translational Behavioral Medicine. 2018; 8 (3): 515-521.

32. Kuna ST. The MISSION Act: Challenges to VA sleep medicine and other VA specialties. American Journal of Respiratory and Critical Care Medicine. 2019; 200(6):663-4.

Publisher's Note: Springer Nature remains neutral with regard to jurisdictional claims in published maps and institutional affiliations. 